\title{
Placing your faith on the betting floor: Religiosity predicts disordered gambling via gambling fallacies
}

\author{
HYOUN S. KIM ${ }^{1}$, ALEXANDRA SHIFRIN ${ }^{2}$, TRAVIS SZTAINERT ${ }^{3}$ and MICHAEL J. A. WOHL ${ }^{4 *}$ \\ ${ }^{1}$ Department of Psychology, University of Calgary, Ottawa, ON, Canada \\ ${ }^{2}$ Department of Psychology, University of Guelph, Guelph, ON, Canada \\ ${ }^{3}$ Gambling Research Exchange Ontario, Guelph, ON, Canada \\ ${ }^{4}$ Department of Psychology, Carleton University, Ottawa, ON, Canada
}

(Received: October 23, 2017; revised manuscript received: January 18, 2018; second revised manuscript received: February 19, 2018; accepted: March 11, 2018)

\begin{abstract}
Background and aims: We examined the potential role religious beliefs may play in disordered gambling. Specifically, we tested the idea that religiosity primes people to place their faith in good fortune or a higher power. In the context of gambling, however, this may lead to gambling fallacies (e.g., erroneous beliefs that one has control over a random outcome). People who are high in religiosity may be more at risk of developing gambling fallacies, as they may believe that a higher power can influence a game of chance. Thus, this research investigated the relationship between religiosity and gambling problems and whether gambling fallacies mediated this relationship. Methods: In Study 1, we recruited an online sample from Amazon's Mechanical Turk to complete measures that assessed the central constructs (religiosity, disordered gambling, and gambling fallacies). In Study 2, we conducted a secondary analysis of a large data set of representative adults $(N=4,121)$ from a Canadian province, which contained measures that assessed the constructs of interest. Results: In Study 1, religiosity significantly predicted gambling problem. Conversely, there was no direct relationship between religiosity and gambling in Study 2. Importantly, a significant indirect effect of religiosity on disordered gambling severity through gambling fallacies was found in both studies, thus establishing mediation. The results remained the same when controlling for age, gender, ethnicity, and socioeconomic status for both studies. Discussion and conclusion: These findings suggest religiosity and its propensity to be associated with gambling fallacies, which should be considered in the progression (and possibly treatment) of gambling.
\end{abstract}

Keywords: gambling fallacies, religiosity, gambling problems

\section{INTRODUCTION}

Being devoted to the beliefs of one's religion (i.e., religiosity; Esso \& Dibb, 2004) has been shown to be a protective factor for engaging in addictive behaviors. Indeed, a growing body of literature suggests that people who are religious are less apt to smoke or gamble (Ellison \& McFarland, 2011; Hodge, Andereck, \& Montoya, 2007; Hoffmann, 2000; Islam \& Johnson, 2003). One reason put forth for the positive relationship between religiosity and health is that the religious doctrine provides people with a sense of meaning in life, which facilitates positive living (Krause, 2003; Pargament, 1997). Contrary to this favorable view of religiosity, as it relates to health and well-being, is the evidence that suggests symptoms of disordered gambling elevated among the religious (Binde, 2007; Kaplan, 1978; Lam, 2006). Thus, although religiosity buffers against initiating gambling, problems may be more likely to develop among the religious once gambling is initiated.

The purpose of this research was twofold. First, we directly examined whether religiosity is positively associated with disordered gambling. Second, we examined a possible mechanism for the religiosity-disordered gambling link. Specifically, we hypothesized that people who are religious may place their faith in a higher power - a higher power that will intervene to ensure they will experience positive events in their life. For example, people who place their faith in higher power believe that it is possible for that higher power to intervene in cause-effect relationships (e.g., asking God to heal a terminal cancer patient; Norenzayan \& Hansen, 2006). In the context of gambling, however, a belief that a higher power will intervene in games of chance may manifest as gambling fallacies (e.g., a belief that luck can be harnessed to maximized outcomes). As such, we tested a model in which the association between religiosity and symptoms of disordered gambling is mediated by the belief that a higher power may intervene to influence the outcome of a game of chance (i.e., gambling fallacies).

* Corresponding author: Michael J. A. Wohl; Department of Psychology, Carleton University, 1125 Colonel By Drive, Ottawa, ON K1S 5B6, Canada; Phone: +1 902520 2600/2908; Fax: +1 613 520 3667; E-mail: michael.wohl@carleton.ca

This is an open-access article distributed under the terms of the Creative Commons Attribution-NonCommercial 4.0 International License, which permits unrestricted use, distribution, and reproduction in any medium for non-commercial purposes, provided the original author and source are credited, a link to the CC License is provided, and changes - if any - are indicated. 


\section{THE COMPLEX RELATIONSHIP BETWEEN RELIGIOSITY AND GAMBLING}

Gambling has a long history of being in the "unhealthy" books of many religious groups (Aasved, 2003). Gambling tends to be perceived as an activity that is associated with greed and temptation, the misuse of money, and having a poor work ethic (Binde, 2007; Ellison \& McFarland, 2011). Given the negative light that is placed on gambling among religions, it should be expected that the rate of gambling is low among religious people. Indeed, a small body of research suggests that religiosity has a prophylactic effect on disordered gambling (Ellison \& McFarland, 2011; Hodge et al., 2007; Hoffmann, 2000; Koorn, 2011). That is, religiosity shields people from disordered gambling by placing psychological barriers on engaging in gambling in the first place. In support of this contention, Hoffmann (2000) found that people high in religious participation were less likely to report gambling problems.

Herein, we argue that religiosity may facilitate problem gambling among those who already engage in play. Circumstantial evidence for our general hypothesis comes from Kaplan (1978), who examined the religiosity of American lottery winners of the grand prizes. He found that one third of the lottery winners believed that divine or mystical forces positively influenced their success. Similarly, Lam (2006) found a positive relationship between importance of faith and gambling frequency among individuals who engaged in lottery gambling. Binde (2007) argued that religiosity may increase gambling, because people who are religious place their faith in a positive outcome on a higher power. Gamblers who are religious may feel that higher power will help maximize their success at gambling, despite the objective odds of success. In other words, people who are religious may be more susceptible to developing gambling fallacies.

\section{THE POTENTIAL MEDIATING ROLE OF GAMBLING FALLACIES}

Religion and gambling have certain elements in common, such as the belief that a person has control over external and uncontrollable events, either through one's own ability or a deity (Binde, 2007). People who engage in these types of thinking are more likely to have gambling fallacies (e.g., belief that a lucky person can positively influence the odds of success), which are the risk factors in the onset of gambling problems (Toneatto, Blitz-Miller, Calderwood, Dragonetti, \& Tsanos, 1997; Wohl \& Enzle, 2002; Wohl, Young, \& Hart, 2007). Indeed, gambling fallacies (also referred to as erroneous cognitions about gambling) have long been proposed to have an etiological role in the development and maintenance of problem gambling (e.g., Delfabbro \& Winefeld, 2000; Gaboury \& Ladouceur, 1989; Leonard \& Williams, 2016). For example, disordered gamblers are more apt to ignore statistical probabilities of gambling (e.g., base rate neglect and insensitivity to sample size) and believe that the outcomes of games of pure chance can be influenced to maximize positive outcomes (Leonard, Williams, \& Vokey, 2015; Wohl \& Enzle, 2002; Wohl et al., 2007). Importantly, the long-term impact of such illusions of control on gambling has been substantiated with longitudinal methods (Cowie et al., 2017; Yakovenko et al., 2016). Specifically, the risk of developing disordered patterns of gambling is heightened among players who have false beliefs about their ability to control the uncontrollable elements in gambling games.

Although the extant literature has elucidated the important role that both religiosity and gambling fallacies play in the development of disordered gambling, to our knowledge, no research has examined the interplay between religiosity, gambling fallacies, and disordered gambling. Specifically, whether relation between religiosity and disordered gambling is mediated by gambling fallacies is unknown. In this research, we tested the idea that a belief that a higher power can intervene in casually related events will manifest in gambling as a related belief that a higher power can intervene in gambling games to control the objectively uncontrollable. The downstream consequence is likely elevated risk of disordered gambling symptomatology. Herein, we use the umbrella term "gambling fallacies," which include illusion of control. Our hypothesis was tested in two community-based studies. The first study examined the proposed mediation model in a sample of community-based gamblers in the United States. The second study capitalized on existing data from a large representative sample of community gamblers in a Canadian province.

\section{STUDY 1}

The purpose of Study 1 was to test our general hypothesis that religiosity was positively associated with disordered gambling among a sample of community-based gamblers. We also tested whether belief in a higher power manifests in the context of gambling as gambling fallacies. In this way, gambling fallacies would serve as the proximal predictor of disordered gambling. Thus, ultimately, we contend that the relationship between religiosity and disordered gambling is indirect such that it is mediated by gambling fallacies.

\section{Methods}

Participants and procedure. The final sample consisted of 201 gamblers (96 females and 105 males), ranging in age from 18 to 73 years with a mean age of $37.96(S D=12.74)$. In regard to ethnicity, $144(71.3 \%)$ participants selfidentified as Caucasian. The majority of the sample was employed full time $(n=116,57.4 \%)$ and earned between $\$ 15,000$ and $\$ 75,000$ USD $(n=137,68.16 \%)$. About nine participants were eliminated due to missing data and 10 participants were eliminated as they failed two or more attention checks that were embedded within our questionnaire. Furthermore, we checked the data for outliers and none were identified on our variables of interest. Participants were recruited using Amazon's Mechanical Turk (MTurk) system. MTurk is an online tool that allows "workers" to complete small tasks for monetary compensation and has become an immensely popular tool to recruit participants for psychological research (Chandler \& Shapiro, 2016). 
Importantly, Kim and Hodgins (2017) found that MTurk is a reliable and valid method of collecting data from addictions populations, including gamblers. Participants were compensated \$0.50 USD, which is a normative rate on MTurk for psychological studies of similar duration.

A recruitment notice was posted on MTurk inviting people who gamble to take part in an online survey. Interested participants were then redirected to Qualtrics, where participants provided informed consent. Thereafter, participants completed a battery of measures that collected data on societal risks of gambling, including measures of problem gambling severity, gambling fallacies, and the influence of a higher power on gambling.

\section{Measures}

Religiosity. Three items $(\alpha=0.88)$ of our own design were used to assess religiosity via belief in the divine's influence over one's gambling outcomes. These items are as follows: "There is often a higher power looking over me when gambling," "There is a divine presence that guides my gambling," and "My gambling is not influenced by a higher power" (reverse-coded item). Items are anchored at 1 (strongly disagree) and 5 (strongly agree). An average score was created with a higher score reflecting greater religiosity.

Gambling fallacies. The Gambler's Beliefs Questionnaire (Steenbergh, Meyers, May, \& Whelan, 2002) is a 21-item scale that measures the extent to which people believe that gambling-related outcomes can be influenced to maximize success. For brevity - which is required for research on MTurk - we randomly selected the four items $(\alpha=0.81)$ from the full scale. These items are as follows: "My choices or actions affect the game on which I am betting," "I have a 'lucky' technique that I use when I gamble," "There are certain things I do when I am betting (e.g., tapping a certain number of times, holding a lucky coin in my hand, crossing my fingers, etc.), which increase the chances that I will win" and "I am pretty accurate at predicting when a 'win' will occur." Items are anchored at 1 (strongly disagree) and 7 (strongly agree). An average score was created with a higher score reflecting greater belief that gambling-related outcomes can be influenced to maximize success.

Problem gambling severity. We used the 9-item $(\alpha=0.91)$ Problem Gambling Severity Index (PGSI; Ferris \& Wynne, 2001) to assess the severity of gambling problems. The items on the PGSI are anchored from 0 (never) to 3 (almost always) and assess gambling-related consequences in the past 12 months (e.g., "Have you felt guilty about the way you gamble or what happens when you gamble?"). A total score is calculated based on participants' responses with higher scores indicating greater gambling severity.

\section{Ethics}

The study procedures were carried out in accordance with the Declaration of Helsinki. The Carleton University Research Ethics Board approved the study. All participants were informed about the study and all provided informed consent.

\section{Results}

Regression analyses were performed with gambling problems as the dependent variable and religiosity and gambling fallacies as the predictor variables (see Table 1 for descriptive statistics and Table 2 for regression analyses). As hypothesized, the results of the regression analysis indicated that religiosity significantly predicted the gambling problems, $B=0.07, F(1,196)=12.64$, $p<.001, R^{2}=.06$. We also found support for our hypothesis that religiosity is associated with greater gambling fallacies, $B=0.47, F(1,199)=58.63, p<.001, R^{2}=.23$. Similarly, gambling fallacies significantly predicted gambling problems, $B=0.12, F(1,196)=37.71, p<.001$, $R^{2}=.16$, such that greater levels of gambling fallacies were associated with increased severity of gambling problems.

To test our mediation model, we used Preacher and Hayes' (2004) PROCESS Model 4 bootstrapping method with 5,000 iterations to obtain $95 \%$ bias-corrected confidence intervals (CIs). The results provided support for our hypothesized mediation as religiosity had a significant indirect effect on gambling problems through gambling fallacies, $b=0.56, S E=0.14,95 \%$ CI $[0.32,0.90]$ (Figure 1). In fact, the direct effect between religiosity and gambling problems was no longer significant when gambling fallacies were included in the model.

Table 1. Correlations between measured variable with means and standard deviations on the diagonal: Study 1

\begin{tabular}{lllc}
\hline & Religiosity & $\begin{array}{c}\text { Gambling } \\
\text { fallacies }\end{array}$ & $\begin{array}{c}\text { Problem gambling } \\
\text { severity }\end{array}$ \\
\hline $\begin{array}{c}\text { Religiosity } \\
\text { Gambling } \\
\text { fallacies }\end{array}$ & $2.32(1.46)$ & & \\
$\begin{array}{c}\text { Problem } \\
\text { gambling }\end{array}$ & $0.48^{* *}$ & $3.47(1.44)$ & \\
severity & & $0.40^{* *}$ & $3.73(4.79)$ \\
\hline
\end{tabular}

Note. Non-parametric Tau B's correlations were calculated due to the skew of problem gambling severity and the pattern of results remained the same.

$* * p<.01$ level (two-tailed).

Table 2. Summary of regression analyses predicting problem gambling severity

\begin{tabular}{lrcccr}
\hline Variable & $B$ & $S E$ & $R^{2}$ & $p$ & \multicolumn{1}{c}{$F$} \\
\hline Study 1 & & & & & \\
Religiosity & 0.07 & 0.02 & .06 & $<.001$ & 12.64 \\
Gambling fallacies & 0.12 & 0.02 & .16 & $<.001$ & 37.71 \\
Study 2 & & & & & \\
Religiosity & -0.06 & 0.20 & .01 & .77 & 0.09 \\
Gambling fallacies & 0.25 & 0.05 & .09 & $<.001$ & 28.97 \\
\hline
\end{tabular}

Note. B: unstandardized regression coefficient; $S E$ : standard error; $R^{2}$ : squared multiple correlation coefficient; $p$ : significance; $F: F$ statistic. 


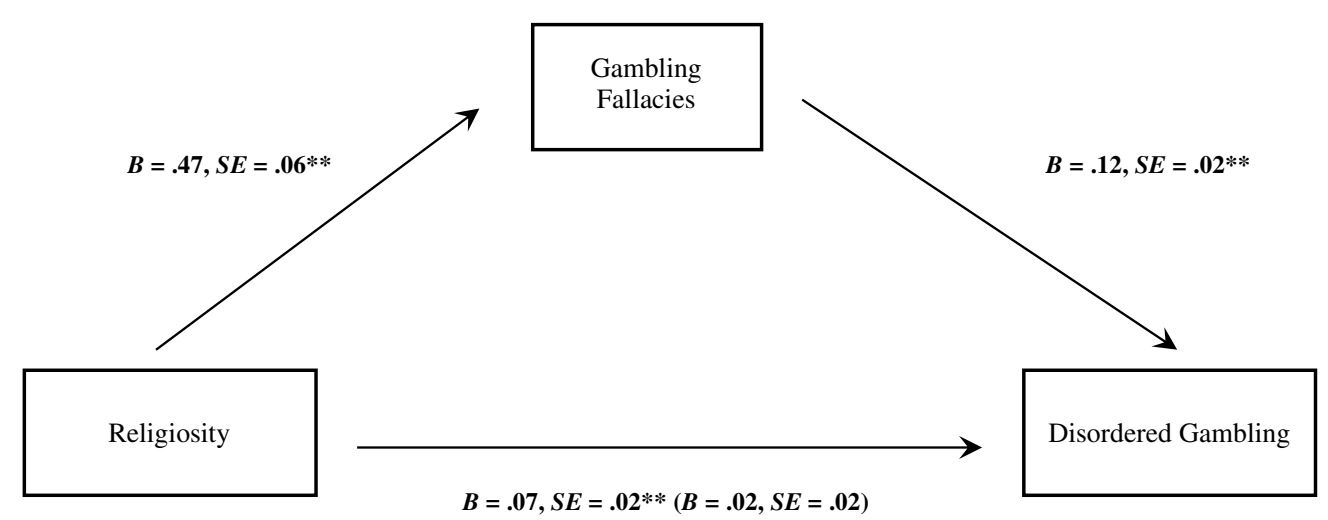

Figure 1. Mediation model with religiosity as the independent variable, gambling fallacies as the mediator, and disordered gambling as the dependent variable among a sample of community-based gamblers: Study 1 . The unstandardized coefficients and standard error shown in parentheses reflect the inclusion of the mediator in the equation. Two asterisks indicate a significant path, $p<.001$

\section{Discussion}

The results of Study 1 replicated previous findings (Binde, 2007; Kaplan, 1978; Lam, 2006) by demonstrating that belief in a higher power is associated with elevated symptoms of disordered gambling. Importantly, however, we found that the religiosity-disordered gambling link is indirect. Specifically, belief in a higher power is positively associated with gambling fallacies that reflect a belief in the controllability of objectively uncontrollable outcomes in games of chance. A potential reason for this finding could be due to that people who are willing to believe that life events can be positively influenced by a higher power are also more apt to believe that the same higher power can intervene in games of chance. In other words, willingness to suspend traditional cause-effect logic in one's religious life is correlated with willingness to suspend traditional cause-effect logic in games of chance. Unfortunately, when such logic is suspended while gambling, problematic gambling behaviors are likely to develop.

Although Study 1 provided support for our hypothesized mediation model, it was limited that our sample was recruited from MTurk, which is not a representative sample (Chandler \& Shapiro, 2016). A further limitation of Study 1 was that our measure of religiosity was specific to religious beliefs within a gambling context (i.e., belief that a higher power can help maximize gambling-related outcomes), which may have inflated our hypothesized associations between religiosity, gambling fallacies, and disordered gambling. Thus, Study 2 aimed to address these limitations through a secondary analysis of representative adults from a large Canadian province, which used a general measure of religiosity (i.e., a measure that did not associate religiosity to the gambling context).

\section{STUDY 2}

The purpose of Study 2 was to conceptually replicate and address the limitations of Study 1. To this end, we capitalized on having access to data from a large-scale study of gambling and problem gambling conducted in the Quinte region of Ontario, Canada. The sample was representative of the demographic profile of the Canadian adult population, and the geographic region had similar gambling opportunities to the rest of Canada. Importantly, the survey used in the Quinte Longitudinal Study of Gambling and Problem Gambling (QLS; Williams et al., 2015) contained measures that assessed the central constructs examined in Study 1 (religiosity, gambling fallacies, and symptoms of disordered gambling).

\section{Methods}

Sample. The QLS is a 5-year longitudinal study that followed a sample of 4,121 adults in Ontario, Canada from 2006 to 2011. The sample was recruited through random digit telephone dialing and age and gender quotas were used to ensure a representative sample of the Canadian adult population. About $26 \%$ of the sample was recruited based on their high levels of gambling involvement. These at-risk gamblers were oversampled to ensure that a sufficient number of participants in the sample developed gambling-related problems during the duration of the study. The sample consisted of 1,867 males and 2,254 females ranging in age from 18 to 80 years $(M=46.07, S D=14.11)$. Similar to Study 1 , the majority of the sample reported being married $(n=2,393,58.1 \%)$, being employed full-time $(n=2,141,52.0 \%)$, and reported an annual income between $\$ 20,000$ and $\$ 70,000$ CDN $(n=2,395,58.12 \%)$. Participants completed an online questionnaire once a year either online, at home, or at the QLS office. A total of $88.7 \%$ participants completed all assessments. For information regarding data cleaning, please refer to the QLS Data User Manual (Williams et al., 2014).

In this research, we restricted analysis to the first wave of assessments. This was done because religiosity was measured only once throughout the study (at the initial assessment) and was not measured in subsequent waves. Therefore, the only time where all three measures were assessed was during the first wave of data collection.

\section{Measures}

Religiosity. A general measure of religiosity was assessed using the Rohrbaugh Jessor Religiosity Scale (RJRS; Rohrbaugh \& Jessor, 1975). The RJRS contains nine items 
$(\alpha=0.90)$ that assess the influence that religion has on a person's life, the strength of their religious beliefs, and the extent of their religion participation. The first item determines the participants' religious affiliation by providing nine possible options (e.g., Catholic, Muslim, Atheist, and other). The second item inquires how often the person has attended religious services during the past year; this item was anchored at 0 (not at all) to 6 (more than once a week). The rest of the items are multiple choice questions with five possible options that vary per question. Examples of these items include: "How much influence would you say that religion has on the way that you choose to act and the way you choose to spend each day?" and "Which of the following statements comes closest to your belief about God?" As items 1 and 2 are not scaled, to provide a measure of participants' religiosity, items 3-9 were summed to provide a measure of religiosity, with higher scores indicating greater religiosity.

Gambling fallacies. The Gambling Fallacy Measure (GFM; Leonard \& Williams, 2016) was used to assess gambling fallacies. The GFM contains 10 items $(\alpha=.88)$ that assess several gambling fallacies, including the belief that one is luckier than others ("How lucky are you? If 10 people's names were put into a hat and one name was drawn for a prize, how likely is it that your name would be chosen?") and illusion of control ("Do you think your chances of winning a lottery are better if you are able to choose your own numbers?"). Each item is a multiplechoice question that contains only one correct answer; the more items the participant answers correctly, the less amount of gambling fallacies they have. For ease of interpretability, an average score was created and inversed so that a higher score reflecting greater belief that gambling-related outcomes can be influenced to maximize success.

Problem gambling severity. To assess symptoms of problem gambling, the QLS contained the 14-item ( $\alpha=$ 0.81) Problem and Pathological Gambling Measure (PPGM; Williams \& Volberg, 2010, 2014). The PPGM classifies participants into five categories: non-gambler, recreational gambler, at-risk gambler, problem gambler, and pathological gambler. Items are dichotomous with the options "yes" or "no." In this research, participants' scores were summed to provide a continuous measure of gambling severity.

\section{Results}

Regression analyses were performed with gambling problems as the dependent variable and religiosity and gambling fallacies as the predictor variables (see Table 2 for descriptive statistics and Table 3 for regression analyses). Contrary to Study 1, religiosity was not significantly associated with disordered gambling, $B=-0.06, F(1,3205)=$ $0.09, p=.77, R^{2}=.001$. However, religiosity significantly predicted gambling fallacies, $B=0.02, F(1,3957)=33.52$, $p<.001, R^{2}=.01$, such that individuals high in religiosity reported greater amount of gambling fallacies. Additionally, gambling fallacies were significantly associated with disordered gambling, $B=0.25, F(1,3328)=28.97, p<.001$, $R^{2}=.01$. As the hypothesized model specified that the effect of the religiosity (the independent variable) on symptoms of
Table 3. Correlations between measured variable with means and standard deviations on the diagonal: Study 2

\begin{tabular}{cccc}
\hline & Religiosity & $\begin{array}{c}\text { Gambling } \\
\text { fallacies }\end{array}$ & $\begin{array}{c}\text { Problem gambling } \\
\text { severity }\end{array}$ \\
\hline $\begin{array}{c}\text { Religiosity } \\
\text { Gambling }\end{array}$ & $\begin{array}{c}12.59(6.64) \\
0.09^{* *}\end{array}$ & $4.10(1.48)$ & \\
fallacies & & $0.09^{* *}$ & $0.12(0.56)$ \\
$\begin{array}{c}\text { Problem } \\
\text { gambling }\end{array}$ & -0.01 & & \\
severity & & & \\
\hline
\end{tabular}

Note. Non-parametric Tau B's correlations were calculated due to the skew of problem gambling severity and the pattern of results remained the same.

${ }^{* *} p<0.01$ level (two-tailed).

disordered gambling (the dependant variable) is indirect, we proceeded to test the full mediation model. Doing so is in line with Hayes $(2009,2013)$, MacKinnon, Fairchild, and Fritz (2007), and others who argue that assessment of indirect effects via bootstrapping is the most valid test of mediation. To this end, we once again used Preacher and Hayes' (2004) bootstrapping method with 5,000 iterations. As predicted, the indirect effect of religiosity on disordered gambling severity was estimated to lie between 0.001 and 0.002 with $95 \%$ CI $(b=0.001, S E<0.001)$ (Figure 2).

\section{Discussion}

Study 2 accomplished two main objectives. First, and most importantly, we replicated our hypothesized mediation model with a representative sample of adults. Second, Study 2 used different, yet related measures to assess our central constructs (religiosity, disordered gambling, and gambling fallacies) to corroborate the findings in Study 1. Altogether, our results provide converging support that religiosity may be an important etiological factor in the development of disordered gambling, insofar as religiosity may be associated with greater gambling fallacies.

\section{SUPPLEMENTARY ANALYSES}

To rule our alternative explanations for our results, we reran our mediational analyses controlling for potential confounding variables. Specifically, prior research has observed that disordered gambling tends to be more prevalent in young adults (Gupta \& Derevensky, 1998; Welte, Barnes, Tidwell, \& Hoffman, 2008), men (Williams, West, \& Simpson, 2012), certain religious groups (e.g., Catholics; Welte et al., 2008), and people of lower socioeconomic status (Welte, Barnes, Wieczorek, Tidwell, \& Parker, 2001). In addition, religiosity tends to be higher in older adults (Bengston, Silverstein, Putney, \& Harris, 2015), women (Miller \& Stark, 2002), and people of lower socioeconomic status (Schieman, 2010). As such, we reran our mediation analysis for Studies 1 and 2 controlling for age, gender, ethnicity, and socioeconomic status (as measured by personal income). Gambling fallacies remained a significant 


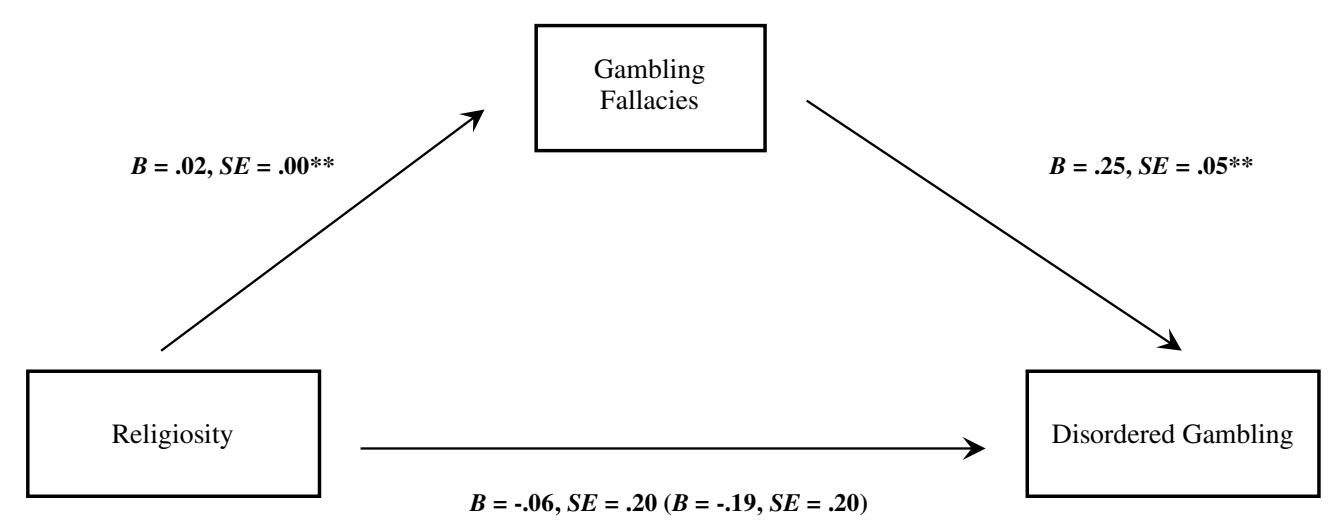

Figure 2. Mediation model with religiosity as the independent variable, gambling fallacies as the mediator, and disordered gambling as the dependent variable among a sample of community-based gamblers: Study 2. The unstandardized coefficients and standard error shown in parentheses reflect the inclusion of the mediator in the equation. Two asterisks indicate a significant path, $p<.001$

mediator of the relation between religiosity and disordered gambling in both Study $1, b=0.24, S E=0.08,95 \%$ CI $[0.09,0.42]$, and Study 2, $b=0.0008, S E=0.0003$, $95 \%$ CI $[0.0003,0.0016]$, thus providing additional evidence for our hypothesized mediation model.

\section{GENERAL DISCUSSION}

Having faith in one's religion is associated with a myriad of health benefits (McCullough, Hoyt, Larson, Koenig, \& Thoresen, 2000), including buffering people from engaging in risky behaviors, such as addictions (Hodge et al., 2007). A potential exception to this rule are the findings that religiosity may increase the risk of disordered gambling (Lam, 2006). Herein, we assessed whether the association between religiosity and disordered gambling is indirect. It was hypothesized that people who are religious may be more likely to believe that they can control the outcome (i.e., through an intervening higher power), despite the objective probability of success, which in turn may increase the risk of disordered gambling. Thus, we contend that gambling fallacies are the more proximal mechanism that explains the religiosity-disordered gambling link.

In two studies, using community samples from two different sources (online, Study 1 and representative adults, Study 2) and different measures to assess the central constructs, we found support for our hypothesized mediation model. Importantly, the hypothesized model held when controlling variables known to vary as a function of disordered gambling symptomatology as well as religiosity (i.e., age, gender, ethnicity, and socioeconomic status). In Study 1, we found that religiosity was associated with gambling fallacies and disordered gambling. Similarly, gambling fallacies were associated with disordered gambling. Importantly, we found support that the relationship between religiosity and disordered gambling may be mediated by gambling fallacies. Study 2 corroborated the findings of Study 1, with the exception that religiosity was not associated with disordered gambling. Variation in the presence of a direct link between religiosity and disordered gambling may be due to the measures of religiosity used in each study. In Study 1, we used items that measured belief in a higher power, which could directly influence the gambling outcomes. In Study 2, we used a general measure of religiosity (i.e., the measure assessed significance of religion in an individual's life, the strength of their religious beliefs, and the extent of their religious participation), which did not make specific reference to the divine's power to influence gambling-related outcomes. It is possible that the religiosity measure used in Study 1 inflated the association between belief in a higher power and disordered gambling severity. Importantly, however, the hypothesized indirect effect was found regardless of the religiosity measures used.

Lastly, it is important to note that the effect size of the mediation model was small. In addition, the portion of the variance explained by the mediation model in Study 2 was smaller than in Study 1. It is possible that the difference between the observed effects in the reported studies can be attributed to the fact that the religiosity measure used differed across the studies. In Study 1, the items referred to the use of the divine while gambling. In contrast, in Study 2 , the items assessed religiosity in general (i.e., not within with the context of gambling). Although the effect size of the indirect effects was small and the measure of religiosity differed in the two reported studies, we have confidence in the findings. This is because the hypothesized mediation model was observed in both Studies 1 and 2, despite the methodological differences. In fact, we believe that the difference in measures used demonstrate the robustness of the hypothesized model.

\section{Implications}

The results of the study suggest that certain aspects of religiosity may be a risk factor for gambling problems, whereas other aspects of religiosity may be a protective factor against gambling problems. For example, previous research has found that individuals high in religious participation were less likely to report gambling problems (Hoffmann, 2000). However, among people of faith who already engage in gambling activities, religiosity may 
increase the risk of disordered gambling. We speculated that the link between religiosity and disordered gambling may be the result of religiosity facilitating the development of gambling fallacies, which have been linked to the risk of disordered gambling. Inherent to religion is the belief that a higher power can intervene to positively influence the cause-effect relations on behalf of the devotee. Although a belief that cause-effect relations can be positively influenced may provide comfort to the religious, problems may develop when transferred to the gambling context. It would behoove researchers to determine which types of gambling fallacies people who are high in religiosity are likely to endorse (e.g., magical thinking and illusion of control). Such information may be helpful in the development of targeted interventions among this potentially vulnerable population.

Our findings may also have some important implications for addressing the development and progression of disordered gambling among people who are high in religiosity. For example, one potential way to reduce gambling fallacies among people of faith who engage in gambling activities is through educational initiatives. It is possible that by providing information about the probability of success in gambling outcomes may reduce the belief that a higher power would intervene during games of chance. However, this assertion requires empirical attention. While believing that a higher power may intervene during times of distress by providing comfort and a sense of control can be adaptive, in the context of gambling, this belief in a higher power may heighten the risk of disordered gambling.

\section{Limitations and Future Directions}

Some limitations should be noted. First, the sample in Study 1 consisted of only individuals who use Amazon's MTurk system. This may affect the generalizability of findings as the sample was not entirely representative of the general community, which we addressed in Study 2. That said, Study 2 is also not without its limitations. The overall response rate for the QLS study was fairly low (21.3\%), thus response bias may have affected our findings. Lastly, the results of our study were based on cross-sectional design, and as such we cannot infer causality between our variables.

Future research would do well to assess the relations between religiosity, gambling fallacies, and problem gambling longitudinally. Doing so would help determine the causal relation between the variables of interest. Second, it would be informative if future research determines which type(s) of gambling fallacies people who are high in religiosity are most likely to endorse (e.g., magical thinking and illusion of control). Previous research has suggested that gambling fallacies consist of two general factors, luck/ chance and skill/attitude, and these fallacies have differing relations to future gambling (Cowie et al., 2017). Increased specificity may help the development of targeted interventions among this potentially vulnerable population. Lastly, it is likely that there are other important variables (e.g., psychological distress) that may influence the relationship between religiosity, gambling fallacies, and disordered gambling. As such, future studies may do well to test whether our hypothesized mediation model holds when controlling for other important confounding variables.

\section{CONCLUSIONS}

This research aimed to determine whether gambling fallacies mediated the religiosity-disordered gambling link. Across two studies, we found support for our hypothesized mediation model. Our findings add to the growing understanding of risk factors in the development of problem gambling by exploring religiosity (a potential risk factor that has received a paucity of empirical attention). These findings may have important implications in developing targeted prevention and interventions for people of faith who engage in gambling activities. Doing so may help people who are high in religiosity maintain the plethora of benefits associated with religiosity, while preventing the development of gambling fallacies and disordered gambling.

Funding sources: No financial support was received for this study.

Authors' contribution: HSK, TS, and MJAW conceptualized the study. AS and TS conducted the statistical analyses. AS wrote the first draft of the manuscript and HSK, TS, and MJAW revised subsequent versions. All authors have read and approved the final draft of the manuscript for submission.

Conflict of interest: HSK and MJAW have received research grants from the Gambling Research Exchange Ontario (GREO). HSK receives a doctoral scholarship from the Alberta Research Gambling Institute. TS is a Knowledge Broker and Content Specialist for (GREO). AS reports no conflict of interest.

\section{REFERENCES}

Aasved, M. J. (2003). The sociology of gambling (Vol. 2). Springfield, IL: Charles C Thomas Publisher, Ltd.

Binde, P. (2007). Gambling and religion: Histories of concord and conflict. Journal of Gambling Issues, 20, 145-165. doi:10. 4309/jgi.2007.20.4

Chandler, J., \& Shapiro, D. (2016). Conducting clinical research using crowdsourced convenience samples. Annual Review of Clinical Psychology, 12(1), 53-81. doi:10.1146/annurevclinpsy-021815-093623

Cowie, M. E., Stewart, S. H., Salmon, J. P., Collins, P., A1Hamdani, M., Boffo, M., Salemink, E., de Jong, D., Smits, R., \& Wiers, R. W. (2017). Distorted beliefs about luck and skill and their relation to gambling problems and gambling behavior in Dutch gamblers. Frontiers in Psychology, 8, 2245. doi:10.3389/fpsyg.2017.02245

Delfabbro, P. H., \& Winefeld, A. H. (2000). Predictors of irrational thinking in regular slot machine gamblers. The Journal of 
Psychology, 134(2), 117-128. doi:10.1080/002239800096 00854

Ellison, C. G., \& McFarland, M. J. (2011). Religion and gambling among US adults: Exploring the role of traditions, beliefs, practices, and networks. Journal for the Scientific Study of Religion, 50(1), 82-102. doi:10.1111/j.1468-5906.2010.01553.x

Esso, N., \& Dibb, S. (2004). Religious influence on shopping behavior: An exploratory study. Journal of Marketing Management, 20(7-8), 683-712. doi:10.1362/0267257041838728

Ferris, J., \& Wynne, H. J. (2001). The Canadian Problem Gambling Index: Final report. Ottawa, ON: Canadian Centre on Substance Abuse.

Gaboury, A., \& Ladouceur, R. (1989). Erroneous perceptions and gambling. Journal of Social Behavior and Personality, 4(4), 411-420.

Gupta, R., \& Derevensky, J. (1998). Adolescent gambling behavior: A prevalence study and examination of the correlates associated with problem gambling. Journal of Gambling Studies, 14(4), 319-345. doi:10.1023/A:1023068925328

Hayes, A. F. (2009). Beyond Baron and Kenny: Statistical mediation analysis in the new millennium. Communication Monographs, 76(4), 408-420. doi:10.1080/03637750903310360

Hayes, A. F. (2013). Introduction to mediation, moderation, and conditional process analysis: A regression-based approach. New York, NY: Guilford Press.

Hodge, D. R., Andereck, K., \& Montoya, H. (2007). The protective influence of spiritual-religious lifestyle profiles on tobacco use, alcohol use, and gambling. Social Work Research, 31(4), 211-219. doi:10.1093/swr/31.4.211

Hoffmann, J. P. (2000). Religion and problem gambling in the US. Review of Religious Research, 41(4), 488-509. doi:10.2307/ 3512317

Islam, S. M., \& Johnson, C. A. (2003). Correlates of smoking behavior among Muslim Arab-American adolescents. Ethnicity \& Health, 8(4), 319-337. doi:10.1080/13557850310001631722

Kaplan, H. R. (1978). Lottery winners: How they won and how winning changed their lives. New York, NY: Harper and Row.

Kim, H. S., \& Hodgins, D. C. (2017). Reliability and validity of data obtained from alcohol, cannabis, and gambling populations on Amazon's Mechanical Turk. Psychology of Addictive Behaviors, 31(1), 85-94. doi:10.1037/adb0000219

Koorn, K. (2011). The roles of religious affiliation and family solidarity as protective factors against problem gambling risk in a Métis sample (Unpublished Master's thesis). University of Guelph, Guelph, ON, Canada.

Krause, N. (2003). Religious meaning and subjective well-being in late life. The Journals of Gerontology Series B: Psychological Sciences and Social Sciences, 58(3), S160-S170. doi:10.1093/ geronb/58.3.S160

Lam, D. (2006). The influence of religiosity on gambling participation. Journal of Gambling Studies, 22(3), 305-320. doi:10.1007/s10899-006-9018-4

Leonard, C. A., \& Williams, R. J. (2016). The relationship between gambling fallacies and problem gambling. Psychology of Addictive Behaviors, 30(6), 694-704. doi:10.1037/adb0000189

Leonard, C. A., Williams, R. J., \& Vokey, J. (2015). Gambling fallacies: What are they and how are they best measured? Journal of Addiction Research \& Therapy, 6(4), 256-266. doi:10.4172/2155-6105.1000256
MacKinnon, D. P., Fairchild, A. J., \& Fritz, M. S. (2007). Mediation analysis. Annual Review of Psychology, 58(1), 593-614. doi:10.1146/annurev.psych.58.110405.085542

McCullough, M. E., Hoyt, W. T., Larson, D. B., Koenig, H. G., \& Thoresen, C. (2000). Religious involvement and mortality: A meta-analytic review. Health Psychology, 19(3), 211-222. doi:10.1037//0278-6133.19.3.211

Miller, A. S., \& Stark, R. (2002). Gender and religiousness: Can socialization explanations be saved? American Journal of Sociology, 107(6), 1399-1423. doi:10.1086/342557

Norenzayan, A., \& Hansen, I. G. (2006). Belief in supernatural agents in the face of death. Personality and Social Psychology Bulletin, 32(2), 174-187. doi:10.1177/0146167205280251

Pargament, K. I. (1997). The psychology of religion and coping: Theory, research, practice. New York, NY: Guilford Press.

Preacher, K., \& Hayes, A. (2004). SPSS and SAS procedures for estimating indirect effects in simple mediation models. Behavior Research Methods, Instruments, \& Computers, 36(4), 717-731. doi:10.3758/BF03206553

Rohrbaugh, J., \& Jessor, R. (1975). Religiosity in youth: A personal control against deviant behaviour. Journal of Personality, 43(1), 136-155. doi:10.1111/j.1467-6494.1975. tb00577.x

Schieman, S. (2010). Socioeconomic status and beliefs about God's influence in everyday life. Sociology of Religion, 71(1), 25-51. doi:10.1093/socrel/srq004

Steenbergh, T. A., Meyers, A. W., May, R. K., \& Whelan, J. P. (2002). Development and validation of the Gamblers' Beliefs Questionnaire. Psychology of Addictive Behaviors, 16(2), 143-149. doi:10.1037/0893-164X.16.2.143

Toneatto, T., Blitz-Miller, T., Calderwood, K., Dragonetti, R., \& Tsanos, A. (1997). Cognitive distortions in heavy gambling. Journal of Gambling Studies, 13(3), 253-266. doi:10.1023/ A:1024983300428

Welte, J. W., Barnes, G. M., Tidwell, M. C. O., \& Hoffman, J. H. (2008). The prevalence of problem gambling among US adolescents and young adults: Results from a national survey. Journal of Gambling Studies, 24(2), 119-133. doi:10.1007/ s10899-007-9086-0

Welte, J. W., Barnes, G. M., Wieczorek, W. F., Tidwell, M., \& Parker, J. (2001). Alcohol and gambling pathology among U.S. adults: Prevalence, demographic patterns and co morbidity. Journal of Studies on Alcohol, 62(5), 706-712. doi:10.15288/ jsa.2001.62.706

Williams, R. J., Hann, R., McLaughlin, P., White, N., King, N., Schopflocher, D., West, B., \& Flexhaug, T. (2014). QLS data user manual. Retrieved from https://dataverse.scholarsportal. info/file. $x$ html;jsessionid=62a8f5545e2d52041 c82e6fe 8819 ? fileId $=8473 \&$ version $=$ RELEASED\&version $=.0$

Williams, R. J., Hann, R., Schopflocher, D., West, B., McLaughlin, P., White, N., King, K., \& Flexhaug, T. (2015). Quinte longitudinal study of gambling and problem gambling. Report prepared for the Ontario Problem Gambling Research Centre, Guelph, Ontario. Retrieved February 20, 2015, from http://hdl. handle.net/10133/3641

Williams, R. J., \& Volberg, R. A. (2010). Best practices in the population assessment of problem gambling. Guelph, ON: Ontario Problem Gambling Research Centre.

Williams, R. J., \& Volberg, R. A. (2014). Classification accuracy of four problem gambling assessment instruments. 
International Gambling Studies, 14(1), 15-28. doi:10.1080/ 14459795.2013.839731

Williams, R. J., West, B. L., \& Simpson, R. I. (2012). Prevention of problem gambling: A comprehensive review of the evidence and identified best practices. Guelph, ON: Ontario Problem Gambling Research Centre and the Ontario Ministry of Health and Long-Term Care.

Wohl, M. J. A., \& Enzle, M. E. (2002). The deployment of personal luck: Illusory control in games of pure chance. Personality and Social Psychology Bulletin, 28(10), 13881397. doi:10.1177/014616702236870
Wohl, M. J. A., Young, M. M., \& Hart, K. E. (2007). Selfperceptions of dispositional luck: Relationship to DSM gambling symptoms, subjective enjoyment of gambling and treatment readiness. Substance Use \& Misuse, 42(1), 43-63. doi:10.1080/10826080601094223

Yakovenko, I., Hodgins, D. C., el-Guebaly, N., Casey, D. M., Currie, S. R., Smith, G. J., Williams, R. J., \& Schopflocher, D. P. (2016). Cognitive distortions predict future gambling involvement. International Gambling Studies, 16(2), 175-192. doi:10.1080/14459795.2016.1147592 